\title{
DEVELOPING METACOGNITION: A BASIS FOR ACTIVE LEARNING
}

\author{
Henk Vos, Dept. Electrical Engineering, University of Twente, Enschede, The \\ Netherlands \\ h.vos@el.utwente.nl \\ E. de Graaff, Faculty TBM. Delft University of Technology \\ e.degraaff@tbm.tudelft.nl
}

\begin{abstract}
The reasons to introduce formats of Active Learning in Engineering (ALE) like project work, problem based learning, use of cases, etc., are mostly based on practical experience and sometimes from applied research on teaching and learning. Such research shows that students learn more and different abilities than in traditional formats of teaching. These abilities are often required by the employers of the alumni and therefore included in the curricula to educate competent practitioners.

A major problem is, however, that a coherent theoretical background explaining the mechanisms underlying ALE is all but lacking. Therefore it is not clear what the developmental objectives of ALE are. A theoretical basis embedded in learning psychology is needed. A promising concept to fill this gap seems the construct of metacognition (Vos, 2001) as distinct from cognition.

Cognition is concerned with what someone knows, metacognition with what persons know about their knowledge (Flavell, 1979; Metcalfe, 1994). Our proposal is that ALE is focused on developing metacognition above or more than cognition. This foundation is important because education for cognitive objectives differs from that for metacognitive ones. Also, metacognitive objectives are more difficult to obtain.

The use of founding ALE in the development of metacognition is that knowledge about metacognition serves to formulate clear goals of ALE. From knowledge about metacognitive development also hints can be derived to raise the effectiveness of ALE.
\end{abstract}

\section{Conceptual background}

In order to lay the connection between ALE and cognition, let us first describe the terms used. In ALE the student is an active participant. The activity of the students is not restricted to using their ears and hands for writing notes, their tongues for answering questions and their eyes for looking to the teacher and the blackboard, and storing away the stuff the teacher tells or shows. ALE requires a lot of activity both mental and physical. The activity is encouraged by the instructional environment: the students are to a certain extent free to choose what they like to do, they may use advanced tools and concepts, attack real problems, work together with experts and teachers, and co-operate in a team. Several educational models apply to one or another form of active learning.

Well known models are Problem Based Learning (PBL) and Project Organized Learning (POL) (De Graaff \& Kolmos, 2003). Both models rely on didactic principles like discovery learning, learning-by-doing (Jerôme Bruner) experiental learning (Kolb) and student centered learning (Carl Rogers). The most important difference between PBL and POL seems to be the resemblance to reality of the treatement of the "problems". In a PBL setting students analyze an ill-defined problem in order to define 
their own learning goals. Solving the problem is a means, not the goal. It simply has to fulfil the function of setting of the learning process. In POL students are expected to learn from solving a problem in a realistic setting. The project is defined by a clear start and a deadline. The subject matter is usually rather well described, as are the goal (the problem to be solved) and the time to be spent on the project.

If the goal and the product to be delivered are defined, as well as the method to produce the product, one speaks of a skills training project (e.g. 'Measure the voltage of various electrical signals with a storage oscilloscope'). If the method can be chosen freely, one speaks of a subject project (e.g. 'Measure the voltage of lightning'). In this case sometimes heuristics can be used (Mettes \& Pilot, 1980).

Sometimes the goal is given but the specific end-product is not as in design projects (e.g. 'Design a flexible route information system for blind people'). If the problem to be solved is not given, but vaguely formulated, ill-defined, or even has to be formulated by the students themselves, one speaks of a problem project (e.g. 'Is metacognition a psychological phenomenon?' or 'What research do you want to do as an exercise and preparation for your final thesis in this field of study?').

Solving a problem does not necessarily involve learning as learning involves a generalization to future, different situations and contexts. Separate attention has to be given to learning goals, both from the viewpoint of the teachers (learning objectives) and the students (learning goals). Being able to specify yourself an ill-defined problem, could be such a learning objective. By formulating the specific problem to be solved themselves, the students attribute meaning to the problem, its solution, and their learning. They determine the cognitive learning goals themselves (self-regulated learning).

Both in PBL and in POL learning is sustained by reflection on the processes, or on the approach to the solution, that took place. Comparing the results to the initial learning objectives and learning goals enhances the learning process (e.g. Cowan, 1998). Sometimes it is helpful to formulate explicit rules for generalization, as in experiential learning according to the learning circle of Kolb $(1976,1984)$. Such techniques can also be applied in learning from case studies and other forms of ALE. In this way the students execute higher level cognitive activities of several types.

Cognition includes knowledge, skills, experiences, and the information in symbolic form that goes with them. Cognition is the faculty of knowing, including being able to write, read, measure, construct, observe, understand instructions for tasks and information. Cognition is related to material objects, to spoken information and/or written material. It is so to say field oriented - in the sense that it relates to observations of phenomena, human signs and artifacts -.

In classical teaching as well as in ALE concepts, skills, exercises, and information are used on a cognitive level. For that ALE is not needed. Classical teaching is based on the required reproduction of cognitive knowledge, skills etc. In ALE there is an extra dimension. Doing the things that are described yourself, giving meaning to what you do and finding sense in it. Asking yourself how and why you do things, and what your motivation is. These aspects include metacognition.

In traditional engineering education the engineer develops a functional way of thinking, a reduction of reality. By giving meaning yourself to what you do, or by changing the meaning, reductionism is broken through. The objects, products, or concepts, acquire multi-functional elements. The engineers are set free to reconstruct reality, matter, technology. They experience a free constructivism. It is important for engineers to make the real world itself tangible, comprehensible, and meaningful, to be 
able to give it (another) meaning or to perceive reality in a different way and change it. Developing metacognition is a conceptual tool for this.

The difference between metacognition and cognition can be expressed as follows.

Metacognition can be considered the faculty of knowing about cognition. It includes:

knowledge of the structure of knowledge, information or tasks; comprehension of text; knowledge about self or others; self-regulation; the feeling of knowing; the use of reflection, etc. Tasks on a metacognitive level are e.g.: To check whether you understand information; To find the information you need for a cognitive task by yourself. Metacognition is related to observation of your own mental states and processes. Learning goals on this level are therefore difficult to formulate.

\section{Metacognitive learning objectives and goals}

Metacognition is oriented on the mental processes that occur with cognition. Therefore learning objectives on a metacognitive level as formulated by teachers, refer to mental states and processes. Since these are very personal and not easily accessible to the teachers, the personal learning goals of the students can differ from the intentions of the teacher. Also extra learning goals emerge like determining your cognitive learning goals yourself, and reducing the real world by yourself to attain these goals.

Some examples of cognitive objectives in education are the following. The student must be able: To define the concept of 'function'; To understand the written information about the forces on a bridge; To apply the concept of electrical power to lightning; To calculate the acceleration of an object from given positions and times; To use a computer, a multimeter, etc. for a specified purpose.

Examples of metacognitive objectives are e.g. being able: To define a newly developed concept; To find structure in some given information; To model reality; To solve real world problems; To design a new product; To regulate your learning yourself. Problems related to these objectives lie on the three higher levels of the Bloom's taxonomy of problems: analysis, synthesis, and evaluation. Such tasks can be executed in several alternative ways, that give some choice and freedom to the students.

Other such metacognitive developmental objectives are that students are able: To pursue their curiosity with respect to nature, technology, human dynamics, and/or society; To find a way to understand a phenomenon that is in conflict with what they learned before; To distinguish between what they already know and what they do not yet know; To develop ways to solve a given problem, compare these, and/or choose the best; To keep the goal in mind during problem solving.

Such objectives require flexibility of the teachers. There is no one good answer in tasks designed to develop metacognition. It is also more difficult to deliberately design instruction for these objectives. Since there is freedom in learning there is also freedom in teaching. This is reflected in different formats for ALE. Nevertheless, some hints for the design (Dijkstra, 1997) of ALE instruction can be gotten from a comparison of teaching for cognitive objectives and metacognitive ones (Brown at al., 1979; ElshoutMohr, 1992; Forrest-Pressley, et al., 1985; Garner, 1987; Hacker et al., 1998; Nelson, 1996; Weinert et al., 1987).

\section{Design rules for ALE instruction}


The difference of working for cognitive goals or metacognitive ones will be clarified with the aid of so-called "educational functions", functions that have to be fulfilled in the processes of teaching and learning by the interaction between the teacher and the student (see Table 1). In this view the teacher and the student form a system for the development of the student. The responsibility to fulfill each of these functions can be either the teacher's (teacher-guided learning, facilitation, coaching) or the student's (self-regulated learning) or a co-operative one (e.g. reciprocal teaching).

Table 1. The implementation of some educational functions for cognitive and metacognitive teaching objectives

\begin{tabular}{|c|c|c|}
\hline $\begin{array}{l}\text { Educational } \\
\text { functions }\end{array}$ & $\begin{array}{l}\text { Implementation for } \\
\text { cognitive objectives }\end{array}$ & $\begin{array}{l}\text { Implementation for } \\
\text { metacognitive objectives }\end{array}$ \\
\hline Motivation & $\begin{array}{l}\text { Appreciating the sense and the } \\
\text { use of the subject matter }\end{array}$ & $\begin{array}{l}\text { Having the will to solve cognitive } \\
\text { conflicts }\end{array}$ \\
\hline Setting objectives & Explicit objectives & Open objectives \\
\hline Support & Just in time information & Just in time feedback \\
\hline $\begin{array}{l}\text { Executing } \\
\text { assignments }\end{array}$ & Doing what is required & Choosing the best way to do it \\
\hline Evaluation & Checking what has been done & Checking whether the direction is right \\
\hline Development & Practicing individually & Practicing together \\
\hline Reporting & Co-operative formulation & Individual description \\
\hline
\end{tabular}

From Table 1 some hints can be derived to help raising the effectiveness of various formats of ALE, for example:

- Intentionally include cognitive conflicts in the subject matter and the assignments.

- Let the students formulate their own learning objectives within the scope of the course (to be distinguished from the teaching objectives of the course or the curriculum).

- Do not give them all information they ask for without consideration but point out possible sources of the information needed, in the beginning (and check on beforehand whether the information really can be found there!).

- Give feedback just before an opportunity to apply this feedback and to improve their next work.

- Do not give the students traditional 'cookbook' labs but let the students compose their own 'cookbook' to carry out an assignment.

- Let the students work together, give them the opportunity to discuss among each other, and also with other groups, but require an individual report (and/or logbook) about what they did and learned.

\section{Discussion and conclusion}

In learning for cognitive objectives the teacher provides certainty. The teacher or an assistant provides e.g. the information needed. Metacognitive learning objectives involve a higher level of uncertainty (cf. Vos, 2001, Chap. 3). The student has to be able to handle this uncertainty: Acquire the information yourself; Get feedback after the use of this information; Do not avoid discussions or cognitive conflicts; Practice together but learn individually. These are typical aspects of ALE. So students are 
trained to accept uncertainty and to keep an open mind. But there are also consequences for teachers.

In classical teaching the learning is teacher-guided and cognitive objectives are learned, since personal cognitive goals usually do not differ much from the curricular cognitive objectives. The metacognitive objectives in ALE involve two varieties. The first one is self-regulated learning for cognitive objectives. Here the metacognitive aspect is the regulation of learning. The other is learning for metacognitive objectives. Both require self-control, to let go the hand of the teacher.

Having nothing to lean on might be frightening at first for the student, but is also unusual for the teacher. It requires a certain form of controlled letting go from the teacher, a state of trust in the student's abilities, that has to be distinguished from and should not to be confused with throwing the students in the deep. This is not an easy process, especially for those who feel themselves more at home in the teacher-guided cognitive domain. ALE requires either a special training or a selection of teachers.

The relation between ALE and the development of metacognition is new, challenging, promising, and asks for further elaboration.

\section{References}

Brown, A.L., Campione, J.C., \& Barclay, C.R. (1979). Training self-checking routines for estimating test readiness: Generalization form list learning to prose recall. Child Development, 50, 501-512.

Dijkstra, S. (1997). The integration of instructional systems design models and constructivistic design principles. Instructional Science, 25, 1-13.

Graaff, Erik de \& Kolmos, Anette (2003). Characteristics of problem-based learning. International Journal of Engineering Education. 19, 5, p. 657-662.

Cowan, J. (1998). On becoming an Innovative University Teacher: Reflection in Action. Buckingham: The Society for Research into Higher Education and Open University Press.

Elshout-Mohr, M. (1992). Metacognitie van lerenden in onderwijsleerprocessen [Metacognition of learners in instructional learning processes]. Tijdschrift voor Onderwijs Research, 17, 273-289.

Flavell, J.H. (1976). Metacognitive aspects of problem solving. In L.B. Resnick (Ed.), The nature of intelligence, pp. 231-235. Hillsdale, NJ: Lawrence Erlbaum Associates.

Flavell, J.H. (1979). Metacognition and cognitive monitoring: A new area of cognitive-developmental inquiry. American Psychologist, 34(10), 906-911.

Forrest-Pressley, D.L., MacKinnon, G.E., \& Waller, T.G. (Eds.) (1985). Metacognition, Cognition, and Human Performance: Vol. 1. Theoretical Perspectives, Vol. 2: Instructional Practice. New York: Academic Press.

Garner, R. (1987). Metacognition and Reading Comprehension. Norwood, NJ: Ablex Publishing.

Hacker, D.J., Dunlosky, J., \& Graesser, A.C. (Eds.) (1998). Metacognition in Educational Theory and Practice. London: Lawrence Erlbaum Associates.

Kolb, D.A. (1976). Learning style inventory. Technical Manual. Boston, MA: McBer.

Kolb, D.A. (1984). Experiential learning: Experience as the source of learning and development. Englewood Cliffs, NJ: Prentice Hall

Metcalfe, J., \& Shimamura, A. (Eds.) (1994). On knowing what we know: Review of metacognition. Cambridge, MA: MIT Press. 
Mettes, C.T.C.W., \& Pilot, A. (1980). Over het leren oplossen van natuurwetenschappelijke problemen (On solving science problems). Unpublished thesis. University of Twente, Enschede.

Nelson, T.O. (1996). Consciousness and metacognition. American Psychologist, 51(2), 102-116.

Vos, H. (2001). Metacognition in higher education. PhD thesis. Enschede: Twente University Press. The thesis can be found on the WWW, URL address: http://www.ub.utwente.nl/webdocs/to/1/t0000011.pdf .

Weinert, F.E., \& Kluwe, R.H. (1987). Metacognition, motivation and understanding. Hillsdale, NJ: Lawrence Erlbaum Associates. 